\title{
Fictional Tellers
}

\section{A Radical Fictionalist Semantics for Fictional Discourse}

\author{
Stefano Predelli*
}

Received: 4 February 2020 / Accepted: 4 May 2020

Abstract: This essay proposes a dissolution of the so-called 'semantic problem of fictional names' by arguing that fictional names are only fictionally proper names. The ensuing idea that fictional texts do not encode propositional content is accompanied by an explanation of the contentful effects of fiction grounded on the idea of impartation. After some preliminaries about (referring and empty) genuine proper names, this essay explains how a fiction's content may be conveyed by virtue of the fictional impartations provided by a fictional teller. This idea is in turn developed with respect to homodiegetic narratives such as Doyle's Holmes stories and to heterodiegetic narratives such as Jane Austen's Emma. The last parts of the essay apply this apparatus to cases of so-called 'talk about fiction', as in our commentaries about those stories and that novel.

Keywords: Fiction; fictional names; narrative; proper names; semantics.

* University of Nottingham

(D) https://orcid.org/0000-0002-8375-4611

Institute of Philosophy, Department of Philosophy. University of Nottingham Nottingham NG7 2RD, United Kingdom.

$\square$ stefano.predelli@nottingham.ac.uk

(c) The Author. Journal compilation (C) The Editorial Board, Organon F.

This article is distributed under the terms of the Creative Commons Attribution-NonCommercial 4.0 International Public License (CC BY-NC 4.0). 


\section{Introduction}

In this essay I present my approach to what is commonly called 'the semantic problem of fictional names'. In section one, I distinguish my topic from a variety of related issues in the philosophy and semantics of fiction. Section two provides a brief description of (referring and empty) proper names, and section three introduces the main component of my approach, namely the thesis that fictional proper names are merely fictionally proper names.

Since what is merely fictional is nothing, the so-called semantic problem of fictional names dissolves: semantics, that is, the actual study of actual expressions, need not confront that which is not an interpretable expression to begin with. This dissolution is a double-edged sword. Surely, if fiction is populated by affairs that fail to encode fully-fledged propositions, an explanation must be provided of our understanding of fictional works. My solution appeals to a resource other than semantic encoding, namely the impartations engendered by a speaker's discursive contributions. I start with actual impartations towards the end of section three, before I move on to fictional impartations in section four.

The first four sections of this essay tackle fictional names from the viewpoint of fiction-making, taking as their exemplars 'Emma Woodhouse' in Jane Austen's Emma, or the occurrences of 'Holmes' in Arthur Conan Doyle's stories. In section five, I move on to an adaptation of my views to the case of so-called talk about fiction, as when, during a discussion of that novel or those stories, we employ 'Emma Woodhouse' or 'Holmes' in our commentaries. My final section concludes with an optimistic note about possible extensions of my approach, and about their relationships with the many properties of fictional discourse that I could not discuss in this essay.

\section{What's the problem?}

Some of us are fiction-makers. And most of us enjoy and discuss what fiction-makers produce. In many instances of making and appreciating fiction we employ language: some fictions are verbal affairs, and many of our reactions to fictions take the form of discourse about fiction. 
Fiction in all of its forms is a rich topic of philosophical investigation. Even leaving aside the important issues raised by the aesthetic and occasionally artistic dimensions of fiction, much remains to be discussed that is of relevance for (among other things) metaphysics, social philosophy, epistemology, or the theory of communication. Even the preliminary issues related to what counts as fiction remain in dire need of clarification. What is required for fiction-making, and in particular for the making of fictions most intimately related to the linguistic domain? Is it sufficient that the prospective fiction-maker intends to engage in fiction-making? Or is some sort of quasi-institutional background required, so that, intend what I like, I may not engage in fiction-making unless I am officially invested with a certain role, or unless I am recognized as a fiction-maker by an appropriate audience? Or else: what does it take for your discourse to qualify as discourse about a particular product of fiction-making - rather than, say, as a piece of journalism, as a commentary about a different fiction, or as something else entirely? Are my intentions to do so sufficient, or are there dedicated occasions and/or linguistic signals that play an important role in these respects? ${ }^{1}$

Some of these issues inevitably end up within the province of linguistic investigation, at least in a wide sense of 'linguistic'. For some, for instance, makers of verbal fiction engage in a special type of speech-act, with its own felicity conditions and its dedicated illocutionary and perlocutionary effects. For others, in contrast, the ways of fiction are an independent specimen among the varieties of language-use, hardly explainable on the model appropriate for assertives, commissives, or declaratives. And so, what is it that lurks in the background of, say, Jane Austen's 1815 inscription of

(1) sorrow came ... but not at all in the shape of any disagreeable consciousness,

and that justifies our taking that inscription as part of her fiction-making effort, rather than as a report on someone's actual state, or as a recollection of her own melancholy? Is her predicament a topic to be assessed from the perspective of speech-act theory, or is it a matter of some utterly idiosyncratic mode of speaking? Or else, in the case of discourse about fiction: what is it

1 For an overview of these questions see for instance (Lamarque and Olsen 1994), (Lamarque 2009), and the sources cited therein. 
that, on certain occasions, allows us to utter (1), thereby reporting on (as we casually put it) 'how things go in the story of Emma'?

These are interesting questions for the philosophy and linguistics of fiction at large, which may well bear interesting relations with some issues commonly subsumed under the heading of 'the semantics of fiction'. But they are not the questions that occupy centre stage in what follows. With remarkable nonchalance, I can thus proceed on the basis of what must surely be relatively solid pre-theoretic intuitions, at least when it comes to central cases such as (1). And so, for one reason or another, when Austen penned (1) as part of her novel Emma, she tokened certain expressions as part of her fiction-making effort, rather than as a scientific report or as page in her personal diary. And, for some reason or other, when you and I token (1), we do so as parts of our talk about Emma, rather than as an instance of journalism or, for that matter, as a mere calligraphic exercise.

Still, after leaving these important issues aside, much with the aforementioned occurrences of (1) remains to be debated that comes closer to the core of the semantics of fiction. For instance, if the occurrence of (1) in Emma is not an exemplar of factual talk, does that leave it utterly indifferent to questions of truth? And, if an affirmative answer to this question is at all correct, does that also apply to our use of (1) in our commentary about that novel? If the latter, but not the former, is 'truth-apt', what distinguishes them? And if we speak truly when we utter (1) on those occasions, what sort of truth is it, if it does not aim at an accurate depiction of any actual state of affairs?

I shall not be able to bypass all of these questions with the same casual attitude with which I disregarded the issues mentioned at the beginning of this section (see in particular section four below). But I can still partially put them on the side at this stage, because my focus will be on yet another issue, one that is most aptly brought to light by examples other than (1). This is so because, at least according to a simple-minded approach, (1) is a

2 For a discussion of speech-act theory from the viewpoint of fiction-making see among many (Ohmann 1971), (Urmson 1976), (Currie 1990), (Davies 2007) and (Currie 2010), and for my own misgivings about certain applications of speech-act theory to fiction (Predelli 2019) and chapter two in (Predelli 2020), with arguments inspired by (Searle 1975). 
general affair having to do with sorrows and consciousness at large: on some occasions, according to (1), sorrows remain unaccompanied by disagreeable consciousness. ${ }^{3}$ So, on the basis of what (1) presumably encodes, we form our picture of what is fictionally the case: according to the story, so we conclude, sadness is sometimes not that unpleasant. If all of this is at least partially on the right track, then, a familiar semantic explanation may well suffice for the identification of the content in question: (1), the sentence tokened in Austen's manuscript and reproduced above, encodes a general proposition about sorrows, shapes, and the like. And it does so on the basis of regularities indistinguishable from those responsible for the interpretation of any other occurrence of that sentence: English nouns such as 'sorrow' or 'consciousness' combine with all the rest so as to give rise to a proposition, according to plain vanilla compositional processes.

Or so I can afford to assume here, since, as announced, my topic is most perspicuously highlighted not by (1), but by its contrast with affairs such as

(2) Emma Woodhouse ... had lived nearly twenty-one years in the world with very little to distress or vex her.

The important contrast between (1) and (2) has to do with the latter's apparent appeal to particularity: (1) may well ponder sorrows and consciousness in general, but (2) seemingly deals with someone in particular, namely the woman picked out by 'Emma Woodhouse'. But if all of this is taken at face value, a familiar problem ensues: since the story of Emma is fictional, there is nothing for 'Emma Woodhouse' to pick out. And so, a fortiori, no particular proposition is to be found, which may even come close to what (2) purports to be encoding. In other words, then, my uncritical optimism when it came to the proposition encoded in (1) must be inappropriate when it comes to (2): now, the matter has to do with proper names rather than with nouns and predicates, and especially with the putative particulars they attempt at designating. ${ }^{4}$

3 Or so I assume for the sake of the example. The tense in (1), for instance, may be interpreted as referring to a particular time or an occasion; this detail may nevertheless safely be left aside for my purposes.

4 I unashamedly depict the theoretical issue under discussion in terms consonant with the so-called direct-reference approach to proper names and particular (or, as 
None of this is to say that names are the inevitable and unique source of this problem. For one thing, at least according to some views, more than a few proper names occurring in fictions unproblematically do what proper names are supposed to do: to cite a trite example, 'Napoleon' in War and Peace refers to Napoleon just as that name does when occurring in a history lecture. ${ }^{5}$ Conversely, and more importantly, names are not the sole harbingers of particularity: if 'Emma Woodhouse' is at all in the business of picking something out, so is presumably 'her', the pronoun that occurs at the end of (2). And so, eventually, what I am about to say will need to be tested against the evidence of putative particularity in general, rather than merely vis a vis instances of naming. But proper names are a good place to start, and they will keep me occupied throughout this essay.

To summarize, then: let us assume that, for one reason or another, some of us are makers of fictions in the verbal domain, and that, for one reason or another, most of us manage to comment about fictions of all sorts. The ensuing linguistic products may well engender a variety of interesting queries, one of which will remain in the spotlight in what follows: how can a sentence such as (2) be at all in the position of encoding a fully-fledged particular proposition, given that the proper name it contains is apparently unable to provide any propositional contribution?

\section{Names, empty and full}

The issue informally depicted in section one plays a central role in the philosophical debates on the semantics of fiction. Preliminarily, then, the problem arguably stems from the apparent clash between the following pre-

they are often called, singular) propositions, even though much of what I am about to say may be rephrased in terms of alternative frameworks. Regarding direct-reference theories see among many (Kripke 1980), (Devitt 1981), and (Kaplan 1989); for adaptations and extensions of my framework consonant with alternative views of names see (Predelli 2020), in particular chapter one.

5 The issue of so-called 'real names' in fiction in independently interesting, see among many (Voltolini 2013), (Motoarca 2014), and (Folde 2017); for my views on the topic see chapter four in (Predelli 2020). 
theoretical notions (together with a few harmless additional hypotheses): (i) the semantic role of a name is that of referring, in the sense that a sentence containing an occurrence of a name $n$ encodes a proposition having to do with $n$ 's referent, (ii) the name 'Emma Woodhouse' in (2) does not refer to anything, and yet (iii) the occurrence in Emma of that sentence encodes an intelligible proposition.

The problem ensues from the widespread impression that, when the intuitions in (i) and (ii) are flanked by some decent additional assumptions, what emerges is that (2) does not encode any fully-fledged proposition, a conclusion that is taken to be incompatible with the insight recorded in (iii). ${ }^{6}$ And that insight appears to be beyond reproach: surely, so the story goes, we follow the sentences in Emma and we eventually 'get the story', that is, we manage to come up with a sequence of fully-fledged, well-endowed propositions. Accordingly, a variety of alternative hypotheses have been put forth, in the attempt at challenging the theoretical assumptions lurking behind either (i) or (ii). For some adversaries of (i), for instance, the propositional contribution offered by a proper name (within and/or without fiction) is not its referent but some sort of different affair, one which may presumably unproblematically be associated with 'Emma Woodhouse'. ${ }^{7}$ Or else, for others, it is (ii) that gets things wrong, given that, for them, 'Emma Woodhouse' refers to no lesser extent than our everyday uses of 'Napoleon' or 'London'.

These attacks against the spirit of (i) and/or (ii) come in a wide variety of flavours, ranging from appeals to Fregean Sinne to even more exotic

6 'Fully-fledged' is here intended as a preliminary informal term of contrast with the notion of a gappy proposition, as in influential current approaches to so-called empty names - see among many (Donnellan 1974), (Braun 1993), (Taylor 2000), (Braun 2005) and (Taylor 2014); see below for my views on the relationships between emptiness and fictionality.

$7 \quad$ For so-called descriptivist approaches to fictional names see for instance (Currie 1990); for (somewhat surprising) gestures in that direction see also (Lewis 1978).

$8 \quad$ See among many (Parsons 1980), (Zalta 1983), and (Deutsch 1985), and, to some extent, the recent wave of so-called artefactualist views of literary characters, for instance (Salmon 1998), (Thomasson 1999) and (Thomasson 2003), and, for a critical discussion, (Yagisawa 2001), (Everett 2005), (Everett 2013), and (von Solodkoff and Woodward 2017). 
takes on proper names, and from inflated metaphysical landscapes populated by merely possible women to invocations of non-existent meddlers in the romantic life of equally non-existent others. The resulting positions deserve their fame, and they have been ably defended by armies of skilled philosophers and practised semanticists. But it would be futile for me to attempt to challenge all of them. For one thing, it would be futile for reasons of space and of my own limitations, since I cannot claim familiarity with all of the theories currently on the market, and since my misgivings with the few with which I am familiar would occupy many tedious pages. For another, my spirit here is constructive rather than critical: my aim is to provide my own positive view on these matters, to sketch some considerations in its favour, and to gesture towards some of its consequences. If you eventually like my view, I shall happily leave it side by side with its competitors.

One thing to note at the outset is that, in its customary form, the semantic quandary raised by (i) and (ii) may not seem to be related to fiction alone. Rather, according to common consensus, the problem with fictional particularity is but one instance of a wider problem, that of emptiness. In this view, 'Emma Woodhouse' may well be non-referring, that is, it may well be an empty name. But so are 'Bozo', as used by me while hallucinating a clown in the corner, or 'Primo', the expression you employ in your vain attempt at picking out the largest prime number. According to widespread agreement, then, all of these cases engender problems of the same type: barring this or that semantic or metaphysical gymnastics, those names' emptiness seemingly entails that the sentences in which they occur do not encode fully-fledged propositions. Yet, so the story continues, they apparently do: 'Bozo is in the corner', to cite but one exemplar, does say something, indeed, to boot, it says something that we legitimately judge to be false. Since no fiction seems to be at issue here, a popular conclusion is that the crux of the problem is not fictionality but emptiness. And so, fiction may well be a site where empty names abound, yet, in this view, the issue will need to be approached independently of the peculiarities of fictionmaking and of talk about fiction. Rather, it will need to be confronted from the viewpoint of naming in general.

I happily take this methodological advice on board, even though, in the end, my considerations about naming will lead me towards the rejection of 
its starting point. For, as will eventually be apparent, for me the issue with (2) is not at all an issue with naming and/or emptiness, but a peculiar question about fiction. But, first, a few comments about proper names and emptiness are appropriate, if only as a term of contrast for that which matters. And so, in the remainder of this section, I leave fiction on the backburner, and I proceed with certain antecedent commentaries about names, full and empty. Armed with my conclusions, I return to (2) and its ilk in section three.

We are pre-theoretically sufficiently well-equipped for identifying names. The central exemplars, at least, are clear enough: affairs such as 'London' or 'Napoleon' occur in particular syntactic positions, they play a certain role in our language, and, typically, they take on a certain shape, with their characteristic capitalized first letter and all the rest. ${ }^{9}$ And, semantically, they appear to be among the expressions we customarily employ so as to pick out particular things, that is, so as to refer. Or more prudently, now that the spectre of emptiness has been brought to light, they are the sort of expressions that purport to refer, even though, as it sometimes happens, things go wrong. Yet, even when all works as it should, an obvious tension seems to emerge from these trivialities: in a nutshell, names are too few qua candidates for naming, that is, qua bearers of a semantically tractable notion of referring.

Homonymy is the name of the game: what we commonly call one name, such as the six-letter 'London', conceals a variety of naming devices, such as that which names the British capital and that which picks out a city in Ontario. These roles, of course, must be distinguished, if equivocations about what is being discussed are to be kept at bay. Admittedly, all of this may initially look like old news, with little of relevance for proper names in particular: after all, a wide variety of other expressions do just that. We call them ambiguous expressions. For instance, the common noun 'bat' may have to do with hitting devices or flying mammals, and it may thus provide very different contributions to the propositions encoded in the sentences in which they occur. That is: 'bat', the three-letter English type, conceals two

$9 \quad$ For general considerations about name-types, proper names, and their semantic treatment, see (Predelli 2017) and the literature cited therein. 
semantic devices, one concerned with wooden sticks, and the other with pipistrelles.

The relationships between homonymy and ambiguity are controversial. Still, what suffices here is that, if the case of 'London' is at all analogous with that of 'bat', it is so for idiosyncratic reasons, having to do with naming in particular. The first point to note in this respect is that homonymy is, in a sense, ambiguity on a massive scale. Nouns and verbs may well ambiguously be associated with a few distinct semantic roles, and they may do so because of what we may casually call 'the conventions of the language'. In English, it so happens that, as the vernacular puts it, the noun 'bat' has two meanings, due to the vicissitudes of etymological development or to the casual attitude of a distracted linguistic ruler. And so, two or three senses end up being enshrined in the dictionary, and that may well be all that needs to be said. An updated dictionary of names, though, would be an utterly unrealistic prospect. At any moment I may choose 'London' as the name of my dog, of a file in my computer, or of the cup on my desk. These uses of 'London' may well circulate only among my closest friends, yet, their unpopularity notwithstanding, they would unquestionably continue to do what a name should do: at least when occurring in my mouth on particular occasions, they would refer to my dog, to my file, or to my cup. Part of the reason why none of this ends up in any dictionary may well have to do with my irrelevant role as language-maker. But a more interesting part of the explanation lies in the fact that any dictionary that took me seriously would end up being unmanageably vast, and, at any instant, already outdated.

For pretty much any theory of names, then, names in the vernacular sense of 'name' may be subject to a full semantic treatment only on the basis of a variety of so-called pre-semantic considerations. ${ }^{10}$ At the very least, a name-type such as the capitalized six-letter sequence 'London' could be assigned a referential role (or an intension, a content, a character, or whatever is deemed to be semantically relevant) only on the basis of some antecedent considerations about ... How these dots ought to be filled is

10 For discussions of the sense of 'pre-semantic' relevant here see (Kaplan 1989), (Perry 2001), and my developments of that idea in (Predelli 2005), (Predelli 2013), and (Predelli 2020). 
controversial: each sufficiently informative way of completing my uncontroversial beginnings inevitably betrays important theoretical commitments about naming, about semantics, and about language. Still, the slogans are familiar enough. For some, what refers (and/or has a content, a character, etc.) is not the six-letter name-like type 'London' but a use of that type on a particular occasion. Or else, it is a token of that type in a certain context, or perhaps that type with respect to such and such situation, circumstance of use, or disambiguation. Be that as it may, the conclusion that matters for me is that, in pretty much anyone's view, what is a proper object of semantic evaluation is not 'London' in isolation, but 'London' together with certain additional parameters.

I need not provide a precise indication of what these parameters are and do. Still, given the facility with which naming procedures take shape, something having to do with the origin of a certain naming practice will inevitably have to play a role. And so, I launched 'London' qua name of my cup a few days ago, whereas 'London' qua name of the British capital had been in circulation for quite some time. And my or your tokens of 'London' will take on a certain referential role depending on their relationships to this or that launching: if you say 'London' on occasions that bear a suitable relation to my recent launch, you will end up referring to my cup, whereas on other occasions, you would have referred to the British capital. In all of its vagueness, much in may well be reminiscent of ideas more interestingly developed in the so-called Historical Theory of reference determination. ${ }^{11}$ But my vague hints will do, since none of the controversies surrounding that theory are of relevance for my aims.

A theoretically biased terminology will also help me to keep my presentation concise: there is one familiar, six-letter long, capitalized name-type, 'London', which may be put to service as a variety of naming devices, that is, for short, as a variety of names in the semantically relevant sense of 'name'. It is a terminology that departs from the vernacular, since in my sense of 'name' there are many names spelled and pronounced as 'London', such as the name of the British capital and the name of my cup. That is,

11 See in particular (Donnellan 1970), (Donnellan 1974), (Devitt 1981) and (Kaplan 1989); for discussions of different aspects of the Historical Theory see among others (Evans 1973), (Berger 2002), (Soames 2003), (Jeshion 2004), and (Sainsbury 2005).

Organon F 28 (1) 2021: 76-106 
different names ensue from different launching episodes, which all appeal to the common, nice-sounding, and easily spelled name-type 'London'. Crucially, nothing in this way of talking aims at smuggling in any controversial views about, for instance, homonymy, the token-type distinction, or the metaphysical conditions for names and words. I speak of name-types such as the six-letter name-type 'London' and of names such as 'London' qua namer of my cup. You may prefer to speak, say, of different uses of the unique homonymous name 'London', with the accompanying warning that what refers is not a name in your sense but its uses or its tokens. Either will do, but my way has the advantage of conciseness.

And so, launchings, those pre-semantic harbingers of naming, are an important object of inquiry. Once again, the details in the study of launchings are controversial, and the names of large African islands and indistinguishable twins have given cause of concern for more than a few theories about name-introduction. ${ }^{12}$ Yet, once again, the details are not important, since a few common-sensical and relatively uncontroversial assumptions will suffice. For one thing, launching may well not be official ceremonies with invested authorities, dedicated scenarios, and accompanying fanfares. But they surely involve some sort of appropriate mental stance, since a distracted token of 'London' as part of a vocal exercise will surely not do as the launch of a name. Talk of intentions, and perhaps of a sufficiently focused attitude, seems to be appropriate, at least if taken with some latitude: I launched a name for my cup when I pronounced 'London' on a certain occasion partly because I did not intend to replicate any previous use of that name-type, and because I accompanied my introduction with a focused stare on the object on my desk.

Perhaps. Be that as it may, it seems clear that procedures of these sort may encounter more than a few glitches, emptiness included. In particular, I may well have uttered 'London' in the spirit of a launcher, and I may well have kept my gaze firmly directed towards the centre of the desk. But I hallucinated, and no cup was in fact there to serve as the referent for my name. There's much one may say about cases such as these, including the idea that I ended up introducing a name for something other than what I

12 The allusion is to the examples in (Evans 1973) and (Sainsbury 2005). 
though, such as the empty central area of my desk or my mental image of the cup (or a merely possible cup, a non-existent cup, or some other extravaganza of this sort). More plausibly, some may opt for an opposite extreme: in the scenario I described, my launching misfired, so that no name was launched, be that a name for an extravagant possible cup or of a figment of my imagination. Most, including myself, tend towards a reasonable compromise: a name has indeed been introduced by my fleeting ceremony, but it is not a name for any metaphysical oddity or, of course, for a cup that is just not there. It is a name all right, but not a name of anything.

And so, empty names may well be a reality that semantics need to confront. And confronting it may not be that easy, as witnesses by the debate on the proper treatment of emptiness and of the semantic problems they might engender. ${ }^{13}$ But the important thing to note is that the launching of an empty name, if any such thing exists, is surely no easier business than the launching of a kosher, run-of-the-mill referring name. The aforementioned vocal exercise that casually tokens 'London', for instance, will not do even for my hallucinatory scenario: there, all the demands of launching were in place, and were zealously answered by my serious intentions, by my most official launching posture, and by my fixed stare towards the object of my mirage. Names, full or empty, are begotten by naming efforts, rather than by casual vocalizations or unfocused musings.

With this platitude, I conclude my detour on proper names at large, and return to my official topic: fictional discourse and 'Emma Woodhouse', as it occurs in (2). For I am now finally in the position of stating the starting point of my approach, and to present what, for me, is the key to the dissolution of the problem posed by (i)-(iii) at the beginning of this section.

\section{Fictional names}

For me, on any decent understanding of launching, Austen did not launch any name whatsoever: her aim was not that of putting forth a referential device, but rather that of making things up. Just as she failed to beget a spoiled young woman, her father, or her walks with Knightley,

13 See the sources on naming and gappyness mentioned in the footnotes above. 
Austen also failed to create her name: in the sense of 'name' that matters here, 'Emma Woodhouse' is made-up, in the sense that it is not a name at all. In a slogan, fictional names are only fictionally names.

Of course, the occurrences of 'Emma Woodhouse' in Emma have a lot in common with proper names: they are not casual scribbles or exercises in calligraphy, and they conform to the graphic, phonetic, and syntactic roles appropriate for name-types. Yet, they do not raise to the status of proper names, since they are not tokened by a process supported by any actual, non-fictional launching. They are not, in other words, objects of interest from the viewpoint of semantics, that is, from the viewpoint of the study of the only names there are, actual names.

I cannot argue directly for this hypothesis since, in the end, it is a factual assumption about the ways of fiction and of fiction-makers. But I can show the direction in which an assumption of this sort should be developed: I can address its prima facie problems, and I can highlight the profitable outcomes it engenders. The problems will need to come first, since my starting hypothesis may well contain much that is intuitive and consonant with common sense, but it also includes something that is, at first, arresting.

Here is the obviously arresting outcome. In the view introduced above, 'Emma Woodhouse' fails to be a name not because it is some other type of interpretable expression. Rather, being a mere name-type unaccompanied by what is needed for its semantic functioning, it is not anything in the position of providing any semantic contribution whatsoever. As a result, (2) does not encode a proposition. It surely does not encode a proposition about any young lady, since none of the components of (2) refers to anything, young ladies included. But it does also not encode any of those less than straightforward affairs that may perhaps be appropriate in the case of empty names, such as a content involving some merely descriptive individual concept, or a proposition including what some semanticists call 'the gap'.

The idea that (2) fails to encode a proposition is arresting because it seems to fly in the face of the alleged intuition recorded in (iii), namely the idea that (2) says something, and that its doing so is a pre-condition for our ability to follow Austen's tale - for our capacity, as we would commonly put it, of 'getting something out of Emma'. And I do not wish to challenge 
this intuition in its entirety. When we read Emma, we do not merely follow the letters on the page, as in an inner recitation of some nonsensical sequence of word-type. Surely, when we read that novel, we understand it, at least in the sense that we eventually construct a certain picture of a charming young woman's interactions with an upright young man and with her petulant father. What I do challenge is an important gloss on this unassailable intuition: the notion that our ability to derive content from Emma may be explained only by the assumption that the sentences in that novel encode propositional content. For, as I am about to explain, content is in general obtainable in ways other than semantic encoding, and those, to an important extent, are the ways that are relevant in the case of fictional discourse.

In section two, I began my considerations with a somewhat lengthy excursus on actual names, such as the referring name 'London' or the empty name 'Bozo'. I did so in order to develop a point of comparison with the idea of fictional names. I adopt a similar strategy when it comes to fictional discourse: the study of discourse (that is, of actual discourse, the only discourse that there is) provides important hints for the treatment of fictionmaking and of the ensuing merely fictional talk. For it is true that, in reality, fictional discourse is no discourse at all, just as fictional women are not peculiar women and fictional names are not a special type of names. But it is also true that fictional women are fictionally women, that fictional names are fictionally names, and that fictional discourse is fictionally discourse. And, as I am about to explain, fictionally just as in reality, discourse may give rise to information in ways different from the encoding of that information in the sentences it includes. So, the discussion of the ways in which actual discourse actually manages to engender content provides an apt preliminary for the explanation of how, in the end, I plan to deal with the intuition in (iii). Once again, then, fiction will remain temporarily on the backburner, and will return to centre stage only after yet another excursus, this time devoted to content-transmission in actual discursive interactions. I say

(3) Paris is in France

and, in standard cases, you understand that, according my contribution, Paris is in France. But you also understand much more besides. For 
instance, by virtue of my utterance, you understand that I can speak, and, given a few additional harmless assumptions, that I can speak English. With only a bit more background in place, you also understand that I have tokened 'Paris' as a name, and hence that I aimed at referring to Paris by means of my token of 'Paris'. Or else, you understand that, according to my utterance, the thing which I named 'Paris' has a certain property, that which I brought to your attention by tokening the English predicate 'is in France'. Hence, among many other things, you understand that, for me,

(4) the bearer of 'Paris' is in France,

or more precisely that the bearer of that token of 'Paris', used in relation to the launching to which I was related on the occasion of speaking, has that property.

Or, at least, you understand all of that if you bother to pay attention to it. Many times, communication is geared towards encoding: in a conversation about geography, the notions that I am speaking and that I am tokening name may well remain mere background noise, an inevitable environmental disturbance whose main purpose is that of encoding a content about the location of a city. But on many other occasions that is not the case. As far as I can recall, none of my utterances of 'she sells seashells by the seashore' had anything to do with the purchase of molluscs, that is, with the encoded content that someone sells seashells by the seashore. Similarly, according to common sense, 'I never utter personal pronouns' has all the flavour of a contradiction, even though the proposition it encodes is the utterly non-contradictory notion that the individual in question has no use for certain expressions. What matters, in the former case, is not the irrelevant encoded proposition, but the notion that the speaker manages to utter certain difficult-to-pronounce types. And, in the second case, what catches our attention is not the plainly non-contradictory encoded content, but its clash with the fact that, in performing that utterance, the speaker has employed 'I', a personal pronoun. ${ }^{14}$

14 For a fuller discussion of these cases see (Predelli 2013); see also certain relevant anticipations in (Castaneda 1957), (Hintikka 1962), and (Kaplan 1989). 
Discourse, then, involves more than the exchange of encoded content. I describe the content conveyed by virtue of (among other things) the act of speaking as imparted content, as opposed to semantically encoded content. And so, the sentence (3) encodes a proposition about the location of Paris, and it encodes nothing about my speaking skills, about my employment of 'Paris', or about any other property of that name. But my utterance of (3) as part of a discursive exchange does, on appropriate conditions, manage to impart that I can pronounce 'Paris', that I use 'Paris' as a proper name, or that 'Paris', as used my me on that occasion, is borne by an entity in France.

As I argue in what follows, the mechanisms of impartation provide a key component of the solution to the aforementioned quandary - that is, it provides the background for the reconciliation of the idea that (2), as it occurs in Emma, is not a proposition-encoding sentence, with the notion that it is in the business of content-transmission. My explanation will nevertheless benefit from momentarily moving away from Emma, and from briefly discussing a different kind of narrative fiction. I elect the hackneyed example of Arthur Conan Doyle's stories as the prototypical exemplar of the sort of fiction that I have in mind.

\section{Fictional tellers and fictional impartations}

Here is an abridged example from the beginning of The Adventures of the Speckled Band:

(5) Holmes turned to his desk and drew out a small case-book.

When it comes to Doyle and to the fictional appellation of his equally fictional creation, (5) follows the meagre semantic pattern displayed by (2): for me, the detective and his name are figments of Doyle's imagination, and figments of imagination are neither detectives nor names. As a result, here as in the case of (2), what confronts the reader is the mere display of a name-type, now the six-letter capitalized type 'Holmes'. And so, here as in the case of (2), what appears in Doyle's text is merely an exemplar of a sentence-type, rather than an instance of a fully-fledged, proposition-encoding sentence. 
Mind you, fictionally, none of this semantic depravation is of any concern to Watson, the utterer. When fictionally occurring in his mouth (or, presumably, his pen), 'Holmes' is a name in the full sense of the term, which he tokens with all the seriousness and intentional involvement required for the use of a name. It is, in other words, a name that reached the good doctor's ears from some sort of distant launching, a launching presumably related to Holmes' baptism and/or to the onomastic customs for the inheritance of a surname. As a result, (5), as fictionally tokened by Watson, is a run-of-the-mill affair, which flanks an unobjectionable verb-phrase with an equally unobjectionable proper name. Fictionally, that is, Watson's inscription is the inscription of a fully-fledged sentence, with all the encoding effects that sentences achieve.

As always, though, fictionality is of no help for us, since what is fictional is nothing: merely fictional names are not names, merely fictional sentences are not sentences, and what is merely fictionally encoded is not anything we may actually understand. As a result, what confronts us, in actuality, is not anything that encodes a particular proposition. For us, there is nothing we could identify as 'the proposition that Holmes turned to his desk' since, in the absence of 'Holmes' and of Holmes, any such would-be particular proposition remains a chimera.

That is not to say that fictionality is of no help whatsoever. After all, what fictionally is the case in The Adventures of the Speckled Band is not only the occurrence of a sentence such as (5). What is also fictionally the case is Watson's use of that sentence - his utterance of it, or his inscription in his private diary. And fictional utterances and inscriptions fictionally engender impartations, just as actual discursive contributions do. So, among other things, Watson's fictional token of (5) imparts that

(6) a bearer of 'Holmes' turned to his desk and drew out a small casebook.

Of course, it only fictionally imparts this much: Watson, his tokens, and his diary are denizens of the fictional domain to no lesser extent than Holmes and his case-book. And so, in reality, nobody is imparting anything to anyone, and, a fortiori, nobody is imparting the proposition that a bearer of 'Holmes' did such and such. But this actual deprivation is now accompanied by a positive result: the fictional occurrence of (5) in Watson's diary 
only fictionally imparts a certain propositional content, but it is a propositional content that we actually understand, believe, debate, or discuss.

In the absence of anything that actually contributes to particularity, then, there is no particular proposition that, as we would casually put it, is about Holmes. But Watson's fictional token of (5) engenders further contentful results. His imparting them may well be merely fictional, but what is being imparted is not. It is, rather, content which we understand, and which we may even encode in our own straightforwardly content-encoding sentences, as I just did when I penned (6): the relation of bearing a name holds between the six-letter type 'Holmes' and an individual who turned to his desk and drew out a small case-book. This, of course, is not the particular proposition we envision as fictionally being encoded in Watson's words. But it a proposition nevertheless, and it is the best we may hope to bring home as a result of our access to Doyle's story.

In a sense, then, fictional telling takes the place of semantic encoding when Watson's tale is at issue: in the absence of any encoded proposition, what catches our attention are the impartations engendered by the teller's tokens. As a result, the idea that fictional names are only fictionally names deals with the intuition in (iii) from section two by giving due prominence to the act of utterance. As (iii) rightly insists, content must be in the air, if our approach to the text is to yield a picture of 'what goes on in the story'. And yet, it is not content encoded in the text, that is, in the would-be sentences it contains, but content imparted by the fictional utterances it depicts. Its analysis, then, is not the province of semantics, that is, of the study of actual proposition-encoding sentences and the equally actual proper names they may contain. The topic, rather, are the communicative effects generated by the fictional act of speaking.

The reason why I momentarily switched to The Adventures of the Speckled Band is that, in this case, fictional telling goes without saying. After all, Doyle's tale is not merely a tale in which an eccentric detective turns to his desk, takes out a small book, and eventually solves yet another baffling crime. It is also, explicitly, a tale in which that detective's sidekick describes his adventures. In a nutshell, The Adventures of the Speckled Band is an instance of homodiegetic narrative. And so, The Adventures wears the effects of impartation on its sleeves: fictionally, the good doctor does not merely do 
this and that with his companion, but also, at some later time, bothers to record his adventures in the text that fictionally occurs before us. ${ }^{15}$

Yet, the idea of fictional telling is no less crucial in the case of Emma. It is so, incidentally, also for reasons that are independent from my take on fictional discourse, and that stem from the standard narratological approach to heterodiegetic narrative. For, surely, the teller that emerges from the pages of Emma is not Austen, the offspring of a Hampshire Anglican rector who eventually died in Winchester at the age of forty-one. It is, rather, a construct whose attitude, gender, demeanour, and tone are to be reconstructed from an attentive interpretive reading of the text. It is, then, a fictional construct. It is, to boot, a fictionally very chatty construct indeed, a teller who reports with almost infallible insight on Highbury's social life. The teller in Emma may take on a fictionally less explicit shape than Watson's, but it is nevertheless there for all of those who bother to access Austen's work. And so, as I am about to explain, the notion of impartation, which served eminently well in the case of The Adventures, also plays a central role in the explanation of our interactions with Emma. ${ }^{16}$

Austen may well have chosen her name-types with the care we expect from authors who leave little to chance. But the name that fictionally echoes in her tale, 'Emma Woodhouse', is not her creation, since that name is simply nothing. Her onomastic attention bears the responsibility for the name-type which, in her fictional teller's mouth, is tokened as the name of a charming young lady. But, for Austen and for us, 'Emma Woodhouse' does not name that lady, or for that matter anything else. Not, mind you, because it is an empty name, but because it is merely fictionally a name. And so, impartation is once again what, for Austen and for all of us, takes on the needed contentful responsibilities: the fictional occurrence of (2) as part of the teller's narration fictionally imparts the sort of content that utterances of that kind generally impart. It does, in particular, fictionally impart that

15 For classic discussions of the homodiegetic/heterodiegetic from the narratological viewpoint see for instance (Genette 1980), (Berendsen 1984), (Bal 1985), (Porter Abbott 2002), (Gunn 2004), (Fludernik 2009), and (Currie 2010).

16 For philosophical discussions of the idea of a teller in heterodiegetic narrative and related exemplars see (Levinson 1996), (Kania 2005), (Carroll 2006), (Warternberg 2007), (Wilson 2007), (Currie 2010), (Wilson 2011) and (Matravers 2014). 
(7) a bearer of 'Emma Woodhouse' had lived merely twenty-one years in the world with very little to distress or vex her.

Of course, it does all of that merely fictionally, since the speaking, the tokening, and the imparting are all made-up. Still, here as in the case of (6), what is being imparted is straightforwardly understandable, negotiable, and debatable: it is a content about the relationship of bearing, about the name-type 'Emma Woodhouse', and about the property of living for more than two decades in a comfortable state.

Once again, then, semantics, that is, actual semantics, is utterly indifferent to (2), as it occurs in Emma. What appears in that novel are merely name-types, such as the four-letter type 'Emma', and mere name-types are not a proper object of semantic investigation. They are, a fortiori, not as important an area of semantic befuddlement as the expressions which some uncritically took to be their natural companions, namely empty names. For empty names are names all right, and their workings are strange affairs that deserve the semanticists' attention. But 'Emma Woodhouse' is not an empty name. To repeat: not because it is a name that names something, but because it is not a name at all.

What is not indifferent to (2), on the other hand, is the theory of impartation, that is, the study of the contentful effects achieved by one's discursive contribution. This is so because we actually contribute to discourse by uttering, by writing, or anyway by tokening this and that, and because all of this is also fictionally the case - as with Watson's use of 'Holmes', or with the tokens of 'Emma' in the discourse fictionally carried out by Emma's teller. What is relevant, of course, is not a theory of action: that someone imparts anything is, in these cases, merely fictional, and merely fictional actions are not actions at all. But the study of actual impartations reverberates in the fictional domain, since that which is fictionally being imparted plays a central role in the explanation of our understanding of fiction. The results, of course, are not the sort of particular propositions fictionally negotiated by those equally fictional tellers, that is, propositions about a particular detective or about a specific young woman. But they do nicely enough when it comes to us, the inhabitant of a domain populated only by what there is, actual propositions included. 


\section{Talk about fiction}

I granted that Austen (and probably Doyle) chose their name-types with some care: surely, 'Emma Woodhouse' does a better job as a prospective fictional name for an English young woman than 'Oliver Cromwell' or 'Paris, Texas'. The authorial display of a name-type is thus not an inconsequential affair, for reasons that may in the end impinge on our appreciation and interpretation of the ensuing fiction. Yet, 'display' aptly emphasizes the semantic inertness of that which Austen tokened two centuries ago, and which we continue to access as we browse through the pages of our copies of her work. What is here, among us, are not uses of a name, but the mere presentation of a name-type.

As far as this essay is concerned, then, propositional encoding may well unproblematically be in place at many junctures of fiction, (1) being perhaps a case in point. And, at least as far as I have argued thus far, bits of propositional contributions may well straightforwardly be in place also in the case of (2), for instance when it comes to the nouns and predicates it contains. But particularity remains a chimera: (2) fictionally encodes a particular proposition about a certain woman, but it only fictionally does so. $A$ fortiori, of course, truth remains a chimera as well, even after general questions of so-called 'truth in fiction' have been settled. As far as I am concerned here, for instance, (1) may well be true in Emma, at least in the pretheoretic sense that, according to that fictional scenario, sorrows may come with no accompanying disagreeable consciousness. ${ }^{17}$ And, as far as this essay goes, (1) may well be false in actuality, as long as sadness is inevitably unpleasant among us, in the real world. In other words, as far as I can tell, (1) may well encode a proposition that conforms to how sorrows happen to be according to Emma, and that fails to accurately depict the ways of sadness in our world. Perhaps. Getting closer to a fully-fledged theory of truthin-fiction remains nevertheless superfluous when it comes to my main target: for me, sentences such as (2) are not in the business of truth or falsehood for the fundamental reason that they do not encode propositions. And so, even taking for granted some decent approach to the idea of "true in

17 For a small sample of the extensive literature on narrative reliability see (Booth 1961), (Prince 1987), (Currie 1995), and (Nunning 1999). 
Emma' (or, for that matter, of 'actually true'), there is simply nothing with (2) that qualifies as (true, false, or whatever) propositional content.

I have swiftly mentioned issues of truth not because they play an immediately relevant role in my account of Emma and of fiction-making, but because they may seem to raise independent difficulties when it comes to another type of occurrence of (2), namely its occurrence as part of our talk about fiction. And so, Austen may well have displayed that sentence-type as part of her making up a story. But we do also say things of that kind: if asked how things went with Emma's protagonist, we may do worse than to begin with a similar sounding affair. And here, so the story goes, we surely say something true, just as we would say something false, had we opted for

(8) Emma Woodhouse had lived nearly forty years in the world

instead. Since truth is unachievable in the absence of propositional content, so this objection continues, there must be an explanation of how (2) or (8) encode propositions, and a fortiori of how 'Emma Woodhouse' contributes to them. At least when it is part of our talk about fiction, then, 'Emma Woodhouse' must be a proper object of semantic investigation, and it may not be reduced to the status of a merely fictional name.

The assumption lurking behind this objection is appropriate: no theory of fictional names is complete, unless it addresses their occurrences in cases of talk about fiction. That objection's target is however inappropriate since, as I am about to argue, the approach to Austen's display presented above may also be extended to occurrences of (2) in our mouths, that is, in the mouths of those who are not fiction-makers. In order to introduce my take on talk about fiction, I must nevertheless begin with a further detail in my analysis of fiction-making, having to do with the issue of co-reference.

In actuality, we freely re-employ names in order to refer to the same individual. I say 'Oliver Cromwell was born in 1599; in 1650 Cromwell lead the Irish campaign', and you understand that a certain man was born at the end of the $16^{\text {th }}$ Century and directed a particular military campaign. Or, at least, you do so on the basis of the usual hypotheses about co-reference: in the absence of indications to the contrary, it is eminently reasonable to suppose that, as I moved past my first sentence, I did not suddenly decide to employ 'Oliver Cromwell' as the name of the homonymous $20^{\text {th }}$ Century 
mountain climber. Of course, much remains to be said about the actual workings of co-reference, but what matters here is that, whatever regularities are in place in these scenarios also apply to the fictional domain. So, it is surely implausible to suppose that Emma is a confusing tale of massive homonymy, and that her teller seamlessly speaks of a variety of distinct bearers of 'Emma Woodhouse'. In the absence of any plausible reason to the contrary, then, we suppose that all tokens of 'Emma Woodhouse' in Emma fictionally token the same name, and that the sentences in which they occur fictionally encode particular propositions about the same woman. As a result, for us, the ensuing impartations pertain to one and the same bearer of that type: a bearer of 'Emma Woodhouse' had lived nearly twentyone years, and that very same bearer once chatted with her father, went on a walk with an upright young man, and enjoyed meddling in the romantic life of others.

The bounds of co-reference go well beyond the front and back covers of Doyle's or Austen's novels. Since the mechanisms of actual co-reference trickle down to fictional co-reference, I could afford to be utterly uncommittal when it came to anything resembling a theory of co-reference. And so, common sense will do also as an account of inter-fictional co-reference, even though the issue remains independently deserving of closer analysis: for one reason or another, adaptations, sequels, and other similar scenarios proceed on a presumption of co-reference with the original. ${ }^{18}$ Surely, for instance, the fictional bearer of 'Holmes' in Doyle's 1902 tale The Speckled Band is, fictionally, the very same bearer of that name in his 1891 A Scandal in Bohemia, and the fictional bearer of 'Watson' is the very same fictional doctor across all of the canon. And, incidentally, they are so even if they end up satisfying importantly different properties in this or that tale - or, as in the infamous case of his war-wound, even if what is fictionally true of Watson in one story flatly contradicts what is fictionally true in another. ${ }^{19}$

18 Cross-fictional issues have generated an interesting philosophical debate, see for instance (Bjurman-Pautz 2008), (Caplan 2014), and (Friend 2014).

19 The fictional location of Watson's unique war-wound apparently shifts across different stories in the Holmes canon. For discussions of fictional inconsistency see for instance (Walton 1990), (Byrne 1993), (Alward 2012), (Everett 2013), (Matravers 2014), and (Bourne and Caddick Bourne 2016). 
Something clearly must play a determinant actual role in this respect. Perhaps, fictionally, all occurrences of 'Holmes' and 'Watson' across Doyle's stories co-refer because, in actuality, Doyle designed his sequels with a certain intention. Or else: fictionally, the tokens of 'Emma Woodhouse' in Douglas McGrath film adaptation fictionally exemplify the name fictionally uttered by Austen's narrator because, in actuality, it is rewarding or profitable to take them as exemplars of the same name. Or something along these lines, since any decent understanding of the informal ideas of 'telling the same story' or of 'telling another story with the same characters' will do for my purposes. In particular, as I am about to explain, it will do also in the case of our re-telling, as when we summarize Emma by uttering (2). Imagine then that I utter the sentence-type (2) and that, for one reason or another, I aim at reporting how things went in Emma, rather than at commenting about one of the many actual bearers of the name-type 'Emma Woodhouse'. In both cases, a very actual relationship governs my use. But it is a relationship of a very different type. In the case of my remarks about an actual woman, my utterance takes place against the background of a suitable connection between my token and, eventually, the launch of a name spelled and pronounced a 'Emma Woodhouse'. Whereas, in the case of my summary of Emma, what is at issue is my intention to tell the same story, that is, my intention to retell the tale of Emma, rather than to describe the actual course of events or, for that matter, to retell some other story.

What ensues is merely fictional co-reference. Since my actual utterance is appropriately related to Austen's fiction-making, what is fictionally the case is that my teller relates to Austen's teller according to the regularities required for the fictional employment of the same name. As a result, what ensues are circumstance that are, in some important respect, parallel to those appropriate for Austen: not unlike her, I display a sentence-type so as to make it fictional that someone employs a fully-fledged, proposition encoding sentence. Fictionally, then, my reteller reports on the fictional vicissitudes of the individual who, in the story, bears 'Emma Woodhouse'. Fictionally, that is, he encodes the same proposition as that encoded by Emma's teller in her initial description of Emma's age and contentment. But it does so only fictionally, since my tokens of 'Emma Woodhouse' do not aim at replicating any actual name, or, of course, at launching a wholly 
novel appellation. The actual result is, here as before, one of impartation: what my reteller fictionally imparts is that a bearer of 'Emma Woodhouse' had lived nearly twenty-one years, and all the rest. More than that: it imparts that the very same bearer of 'Emma Woodhouse' as the one depicted by Austen's teller did such and such. And so, since no proposition is at issue, fictional retelling is of no greater interest from the semantic viewpoint than fictional telling: the semantic problem of fictional names dissolves in the case of talk about fiction to no lesser extent than in the case of fictionmaking.

Moreover, since no proposition is being encoded, the question of truth fails to arise in either case. But something sufficiently close to truth remains of relevance for talk about fiction, namely fictional truth: my tokens of (2) fictionally provide true descriptions of Emma's world, whereas tokens of (8) do not. They do so because they impart that a bearer of 'Emma' lived happily for twenty years, and because Austen's teller reliably imparted that such a bearer did indeed lead a trouble-free, two-decade long life. Caught in the game, you may well react to my summary with an enthusiastic 'true!'. But, appropriately enough, you would only be playing the game: not unlike my fictional use of (2) as a proposition encoding sentence, your exclamation populates the fictional domain, and the fictional domain alone.

\section{Conclusion}

In this essay, I sketched the main traits of my approach to what is improperly called 'the semantic problem of fictional names'. For me, no such problem arises in connection with either fiction-making or discourse about fiction: fictional names are merely fictional names, and they are thus not anything of concern for the study of actual expressions and of their contentful contributions. My strategy centered around the ideas of launching and impartation, which I briefly discussed in relation to the actual use of language, and which I subsequently adapted to the case of fictional discourse.

Needless to say, much remains to be added to my suggestions. In particular, the following issues strike me as sufficiently closely related to fic- 
tion-making and talk about fiction, and hence as targets for analyses consistent with my general approach. For one thing, my treatment of the homodiegetic/heterodiegetic distinction rested satisfied with a brief discussion of their common traits. Yet, tellers who, like Emma's teller, do not also populate the story-world raise idiosyncratic and independently interesting issues, first and foremost when it comes to names, to launchings, and to particularity. ${ }^{20}$ For another, questions of 'what is true in the story', of narrative reliability, and of cross-fictional co-reference have only been cursorily mentioned, but all of them are deserving of a treatment grounded on the ideas of fictional telling and impartation. ${ }^{21}$ Last but most definitely not least, traditional quandaries more or less related to fiction have simply been put aside in all of the above, including the notorious question of so-called true negative existentials and the problem of prefixed instances such as 'according to Emma, Emma Woodhouse lived for nearly twenty-one years'. ${ }^{22}$ Here, I rest satisfied with the hope of having stirred at least some curiosity for the approach to fictional names that I have sketched in these pages.

\section{References}

Alward, Peter. 2012. Empty Revelations: An Essay on Talk About, and Attitudes Toward, Fiction. Montreal: Mc-Gill-Queen's University Press.

Bal, Mieke. 1985. Narratology: Introduction to the Theory of Narrative. Toronto:

University of Toronto Press.

Berendsen, Marjet. 1984. "The Teller and the Observer." Style 18: 140-58.

Berger, Alan. 2002. Terms and Truth: Reference Direct and Anaphoric. Cambridge, MA: MIT Press.

Bjurman Pautz, Anna. 2008. "Fictional Coreference as a Problem for the Pretense Theory." Philosophical Studies 141: 147-56. https://doi.org/10.1007/s11098007-9156-2

Booth, Wayne. 1961. The Rhetoric of Fiction. Chicago, IL: University of Chicago Press.

Bourne, Craig and Emily Caddick Bourne 2016. Time in Fiction. Oxford: Oxford University Press.

20 For my views on this topic see chapter three in (Predelli 2020).

21 I cover some of these issues in chapters three, four, and six of (Predelli 2020).

22 For my take on these issues see in particular chapter five in (Predelli 2020). 
Braun, David. 1993. "Empty Names." Nô̂s 27: 449-469. https://doi.org/10.2307/2215787

Braun, David. 2005. "Empty Names, Fictional Names, Mythical Names." Nous 39: 596-631. https://doi.org/10.1111/j.0029-4624.2005.00541.x

Byrne, Alex. 1993. "Truth in Fiction: The Story Continued." Australasian Journal of Philosophy 71: 24-35. https://doi.org/10.1080/00048409312345022

Caplan, Ben. 2014. "Serial Fiction, Continued." British Journal of Aesthetics 54: 65-76. https://doi.org/10.1093/aesthj/ayt050

Carroll, Noel. 2006. "Introduction to Film Narrative/Narration". In Philosophy of Film and Motion Pictures, edited by Noel Carroll and J. Choi, 175-84. Oxford: Blackwell.

Castaneda, Hector Neri. 1957. "Some Nonformal 'Logical' Relations." Philosophical Studies 8: 89-92.

Currie, Gregory. 1990. The Nature of Fiction. Cambridge: Cambridge University Press.

Currie, Gregory. 1995. "Unreliability Refigured: Narrative in Literature and Film." Journal of Aesthetics and Art Criticism 53: 19-29. https://doi.org/10.2307/431733

Currie, Gregory. 2010. Narratives and Narrators: A Philosophy of Stories. Oxford: Oxford University Press.

Davies, David. 2007. Aesthetics and Literature. London: Continuum.

Deutsch, Harry. 1985. "Fiction and Fabrication." Philosophical Studies 47: 201-11. https://doi.org/10.1007/BF00354147

Devitt, Michael. 1981. Designation. New York: Columbia University Press.

Donnellan, Keith. 1970. "Proper Names and Identifying Descriptions." Synthese 21: 335-58. https://doi.org/10.1007/978-94-010-2557-7_10

Donnellan, Keith. 1974. "Speaking of Nothing." The Philosophical Review 83: 3-31. https://doi.org/10.2307/2183871

Evans, Gareth. 1973. "The Causal Theory of Names." Aristotelian Society Supplementary 47: 187-208.

Everett, Anothony. 2005. "Against Fictional Realism." Journal of Philosophy 102: 624-49. https://doi.org/10.2307/3655676

Everett, Anthony. 2013. The Nonexistent. Oxford: Oxford University Press.

Fludernik, Monika. 2009. An Introduction to Narratology. London: Routledge.

Folde, Christian. 2017. "Non-Fictional Narrators in Fictional Narrative." British Journal of Aesthetics 57: 389-405. https://doi.org/10.1093/aesthj/ayx026

Friend, Stacie. 2014. "Notions of Nothing". In Empty Representations: Reference and Non-Existence, edited by Manuel Garcia-Carpintero and Genoveva Marti, 307-32. Oxford: Oxford University Press. 
Genette, Gerard. 1980. Narrative Discourse: An Essay in Method. Cornell University Press.

Gunn, Daniel. 2004. "Free Indirect Discourse and Narrative Authority in Emma." Narrative 12: 35-54. https://doi.org/10.1353/nar.2003.0023

Hintikka, Jaakko. 1962. "Cogito Ergo Sum: Inference or Performance?" Philosophical Review 71: 3-32. https://doi.org/10.2307/2183678

Jeshion, Robyn. 2004. "Descriptive Descriptive Names." In Descriptions and Beyond, edited by Marga Reimer \& Anne Bezuidenhout, 591-613. Oxford: Oxford University Press.

Kania, Andrew. 2005. "Against the Ubiquity of Fictional Narrators." Journal of Aesthetics and Art Criticism 63: 47-54. https://doi.org/10.1111/j.00218529.2005.00180.x

Kaplan, David. 1989. "Demonstratives." In Themes from Kaplan, edited by Joseph Almog, John Perry, and Howard Wettstein, 481-563. Oxford: Oxford University Press.

Kripke, Saul. 1980. Naming and Necessity. $2^{\text {nd }}$ edition. Cambridge, MA: Harvard University Press.

Lamarque, Peter. 2009. The Philosophy of Literature. Oxford: Blackwell.

Lamarque, Peter and S. H. Olsen 1994. Truth, Fiction, and Literature. Oxford: Clarendon Press.

Levinson, Jerrold. 1996. "Film Music and Narrative Agency." In Contemplating Art: Essays in Aesthetics, 143-83. Oxford: Oxford University Press. https://doi.org/10.1093/acprof:oso/9780199206179.001.0001

Lewis, David. 1978. "Truth in Fiction." American Philosophical Quarterly 15: 3746.

Matravers, Derek. 2014. Fiction and Narrative. Oxford University Press.

Motoarca, Ioan-Radu. 2014. "Fictional Surrogates." Philosophia 42: 1033-53. https://doi.org/10.1007/s11406-014-9522-1

Nünning, Ansgar. 1999. "Unreliable Compared to What?" In Transcending Boundaries: Narratology in Context, edited by W. S. Grünzweig (ed.), 53-73.

Tubingen: G. Narr.

Ohmann, Richard. 1971. "Speech Acts and the Definition of Literature." Philosophy and Rhetoric 4: 1-19.

Parsons, Terence. 1980. Nonexistent Objects. New Haven, CT: Yale University Press.

Perry, John. 2001. Reference and Reflexivity. Stanford, CA: CSLI Publications.

Porter Abbott, H. 2002. The Cambridge Introduction to Narrative. Cambridge: Cambridge University Press.

Predelli, Stefano. 2005. Contexts. Meaning, Truth, and the Use of Language. Oxford: Oxford University Press. 
Predelli, Stefano. 2013. Meaning Without Truth. Oxford: Oxford University Press.

Predelli, Stefano. 2019. "Determination and Uniformity: The Problem with SpeechAct Theories of Fiction." Erkenntnis 84 (2): 309-24.

https://doi.org/10.1007/s10670-017-9959-2

Predelli, Stefano. 2020. Fictional Discourse. Oxford: Oxford University Press.

Prince, Gerald. 1987. A Dictionary of Narratology. Lincoln, NE: University of Nebraska Press.

Sainsbury, Mark. 2005. Reference Without Referents. Oxford: Oxford University Press.

Salmon, Nathan. 1998. "Nonexistence." Nô̂s 32: 277-319.

https://doi.org/10.1111/0029-4624.00101

Searle, John. 1975. "The Logical Status of Fictional Discourse." New Literary History 6: 319-32. https://doi.org/10.2307/468422

Soames, Scott. 2003. Philosophical Analysis in the Twentieth Century, Volume 2. Princeton, NJ: Princeton University Press.

Taylor, Ken. 2000. "Emptiness Without Compromise." In Empty Names, Fiction and the Puzzles of Non-Existence, edited by Anthony Everett and Thomas Hofweber, 3-16. Stanford, CA: CSLI Publications.

Taylor, Ken. 2014. "The Things We Do with Empty Names: Objectual Representations, Non-Veridical Language Games, and Truth Similitude." In Empty Representations: Reference and Non-Existence, edited by Manuel GarciaCarpintero and Genoveva Marti, 183-214. Oxford: Oxford University Press. https://doi.org/10.1093/acprof:oso/9780199647057.001.0001

Thomasson, Amie. 1999. Fiction and Metaphysics. Cambridge: Cambridge University Press.

Thomasson, Amie. 2003. "Speaking of Fictional Characters." Dialectica 57: 205-23. https://doi.org/10.1111/j.1746-8361.2003.tb00266.x

Urmson, James. 1976. "Fiction." American Philosophical Quarterly 13: 153-57.

Voltolini, Alberto. 2013. "Probably the Charterhouse of Parma Does Not Exist, Possibly not even That Parma." Humana Mente 25: 235-61.

von Solodkoff, Tatjana and Richard Woodward 2017. "To Have and to Hold." Philosophical Issues 27: 407-27. https://doi.org/10.1111/phis.12107

Walton, Kendall. 1990. Mimesis as Make-Believe. Cambridge, MA: Harvard University Press.

Wartenberg, Thomas. 2007. "Need There Be Implicit Narrators of Literary Fiction?" Philosophical Studies 135: 89-94. https://doi.org/10.1007/s11098-0079094-Z

Wilson, George. 2007. "Elusive Narrators in Literature and Film." Philosophical Studies 135: 73-88. https://doi.org/10.1007/s11098-007-9096-x 
Wilson, George. 2011. Seeing Fictions in Film: The Epistemology of Movies. Oxford: Oxford University Press. https://doi.org/10.1093/acprof:oso/9780199594894.001.0001

Yagisawa, Takashi. 2001. "Against Creationism in Fiction." Philosophical Perspectives 15: 153-72. https://doi.org/10.1111/0029-4624.35.s15.8

Zalta, Edward. 1983. Abstract Objects: An Introduction to Axiomatic Metaphysics. Berlin: Springer. 